dies ist, beschreibt Zitelmannn (2004) in der Zusammenfassung der eingangs genannten Frankfurter Vormundschaftsstudie:

„Es bleibt festzuhalten, dass die von den Mündeln und ihren Betreuern geschilderte Praxis der Amtsvormundschaft kaum noch entferne Ähnlichkeiten mit dem geltenden Recht aufweist. Dies gilt für die Justiz, soweit die Auswahl des Vormundes ungeachtet der gesetzlich verbürgten Anhörungsrechte der Kinder erfolgte. Dies gilt ebenso für die öffentliche Jugendhilfe, die den befragten Mündeln mehrheitlich nicht die geringste Orientierung über die Aufgaben ihres Vormundes sowie ihre eigenen Recht ermöglichte. Was schließlich die Ausübung ihrer elterlichen Sorgerechte angeht, wurde auch das Gros der Amtsvormünder ihren Pflichten scheinbar nicht annähernd gerecht. Folgt man den Berichten der Kinder und ihrer Betreuer, verschafften sich die Vormünder vielfach nicht einmal einen persönlichen Eindruck von ihrem Mündel. Damit konnte wohl auch von einer Berücksichtigung der persönlichen Wünsche und Meinungen des Kindes, wie sie das in \ 1626 Abs. 2 BGB $^{16}$ geregelte Erziehungsleitbild vorsieht, keine Rede sein. Die mit der Kontrolle der Vormundschaft beauftragten Fachkräfte in den Behörden und Gerichten beanstandeten diese Praxis anscheinend jedoch nicht. Damit setzte sich paradoxerweise in vielen Fällen das von fehlender Achtung, mangelnder Fürsorge bzw. Überforderung geprägte Verhaltender Eltern nun in unmittelbarer Verantwortung des Staates selbst fort.“17

\footnotetext{
16 Vgl. § 56 SGB VIII, der den Amtsvormund über $\$ 1793$ S. 2 BGB auf $\$ 1626$ Abs. 2 BGB verweist.

17 Zitelmann (2004): Vormundschaft aus der Sicht von Kindern und Jugendlichen - eine Interviewstudie, in Zitelmann/Schweppe/Zenz (Hrsg.), 78
}

\title{
Der Eintritt ins Pflegeheim
}

\section{Hintergründe zu sozialpolitischen Problem- und Fragestellungen bei der vollstationären Versorgung, zur Finanzierung, zur Suche und zum Leben im Heim, zusammengefasst auf einen Blick - sowie zu Forderungen nach Mitentscheidung der Heimbewohner}

\author{
Petra Walter \\ ISBN 978-3-8325-2431-9 \\ 120 Seiten, Erscheinungsjahr: 2010 \\ Logos Verlag Berlin
}

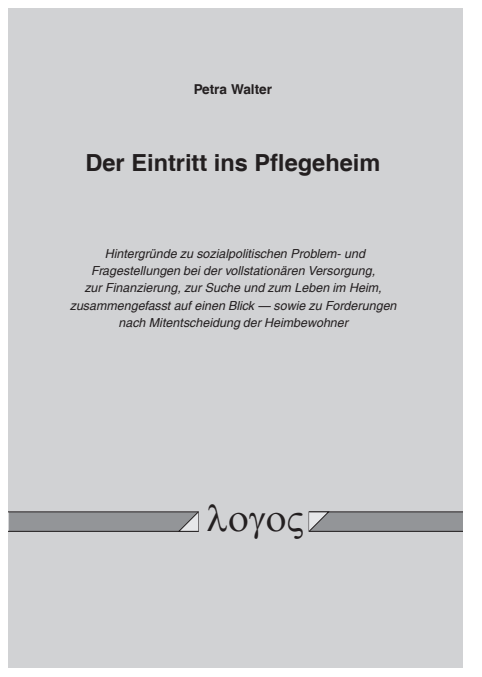

Als Mitglied der früheren nichtständigen Kommission Ältere Menschen des djb freue ich mich, ein Buch vorzustellen, das sich mit den Problemen, die sich aus dem Eintritt in ein Pflegeheim ergeben, eingehend befasst. Deshalb auch der Titel des handlichen Praxisbuchs „Der Eintritt ins Pflegeheim“. Geschrieben wurde es von unserem djb-Mitglied Petra Walter für Angehörige und Betroffene, die mit der Gesamtsituation stationärer Pflegebedürftigkeit konfrontiert werden. Es enthält viele praktische Hinweise und eine Checkliste, die das Auffinden des geeigneten Heims erleichtert.
In dem Buch werden insbesondere die rechtlichen Strukturen zwischen Heimgesetzgebung, Heimvertrag, Pflegeversicherung, Anbietern sowie Kontrollmöglichkeiten dargestellt.

Ein ausführliches Kapitel befasst sich mit den Heimkosten in den Bundesländern und deren verblüffenden Abweichungen.

Im Blickwinkel der Autorin steht immer der (die) Heimbewohner(in) mit seinen (ihren) Bedürfnissen, die in diesem System nicht wahrgenommen werden. Hieraus hat sich ein Forderungskatalog insbesondere nach mehr Mitentscheidungsrechten der Heimbewohner(innen) ergeben, der darauf wartet, umgesetzt zu werden.

Während der Entstehungsphase hat die Autorin ihren Buchentwurf in der früheren nichtständigen Kommission Ältere Menschen vorgestellt und deren Mitglieder mit den zahlreichen aufgefundenen Problemen konfrontiert. Einigkeit bestand darin, die Diskussion weiterzuführen. (Dr. Trude-Lotte Steinberg-Krupp) 